\title{
Estudo de casos de precipitação utilizando o WRF-3DVAR na região sul do Brasil
}

Study of precipitation cases using the wrf3 in the south of Brazil

\author{
Yoshihro Yamasaki, Vinicius Carvalho Beck, Fabricio Pereira Harter \\ Universidade Federal de Pelotas, RS, Brasil \\ yamasaki07722@gmail.com; vonoco@gmail.com ; fpharter@gmail.com
}

\begin{abstract}
RESUMO
Os resultados da assimilação de dados das estações automáticas do INMET e de radiossondagem, da Região Sul do Brasil, na previsão da precipitação e da temperatura pelo modelo WRF - através do método 3DVAR (WRF-3DVAR); analisando em cada caso, se os prognósticos do WRF-3DVAR são mais precisos que os do WRF sem assimilação de dados são apresentados. Os resultados obtidos mostraram a grande importância da assimilação de dados na previsão da precipitação do modelo WRF. Os prognósticos dos perfis verticais, tanto da temperatura do ar como da temperatura do ponto de orvalho, mostraram que a assimilação de dados produziu previsões com estruturas térmicas e úmidas verticais mais realísticas quando comparadas com as observações.
\end{abstract}

Palavras-chave: assimilação de dados, 3DVAR, WRF, precipitação.

\begin{abstract}
The aim of the study has been to evaluate the results of the data assimilation of INMET automatic weather stations and soundings of the southern of Brazil in precipitation and temperature forecasting of predicting of the WRF model by 3DVAR method (WRF-3DVAR), analyzing in each case, whether the WRF-3DVAR forecasts are more accurate than the WRF without data assimilation. The obtained results show the great importance of data assimilation in precipitation prediction of the WRF model. The prognoses of vertical profiles of the air and the dew point temperatures, showed that the data assimilation produced predictions with thermal and moist vertical structures more realistic in the light of the observational soundings.
\end{abstract}

Keywords: data assimilation. 3DVAR, WRF, precipitation. 


\section{INTRODUÇÃO}

Sob o ponto de vista matemático, as soluções do sistema de equações - que regem o comportamento termohidrodinâmico da atmosfera, para a obtenção da previsão numérica do tempo - são obtidas tratando-os como problemas de valor inicial e de contorno. Portanto, quanto mais precisas forem as condições iniciais, mais precisas serão as previsões (LORENZ, 1963). Até meados da década de 1990, os grandes centros mundiais de previsão numérica do tempo empregavam técnicas de interpolação ótima (IO) para a obtenção das condições iniciais no processamento dos modelos de previsão global da atmosfera. No início, a assimilação de dados em modelos numéricos era bastante restrita, especialmente no tratamento de dados de radiâncias espectrais medidas por satélites, visto que estas não eram assimiladas diretamente, pois o que se utilizava eram os parâmetros atmosféricos deles inferidos como a temperatura e a umidade - em adição aos dados de ventos. Foi a partir dessa época que os sistemas de assimilação de dados passaram a ter grande importância, dado o potencial positivo que vinham demonstrando - especialmente quando incluídos dados sobre as vastas regiões oceânicas e em especial no hemisfério sul, que apresenta uma cobertura espacial relativamente pobre em termos de dados de observações convencionais (Rabier et al., 1998).

As técnicas de assimilação consistem, basicamente, em procedimentos que tratam os dados - para melhorar as condições iniciais dos modelos - levando em consideração critérios estatísticos que combinam as observações com a previsão de curto prazo campo de background. A partir das novas condições iniciais, geradas com as estatísticas dos erros de observação e previsão, são feitas novas integrações numéricas dos sistemas de equações dos modelos numéricos de previsão de tempo. As primeiras técnicas foram desenvolvidas com base em parâmetros empíricos para estimar a covariância dos erros das observações e das estimativas. As técnicas atuais são baseadas no método gaussiano dos mínimos quadrados para estimar estas covariâncias (Kalnay, 2003).

Atualmente, as principais técnicas de assimilação de dados empregam metodologias baseadas na teoria da filtragem de Kalman e no cálculo variacional. Há muitas versões, de cada uma destas técnicas; além dos métodos híbridos, que combinam os fundamentos dos métodos básicos e seus derivados. Os métodos de assimilação de dados baseados no cálculo variacional foram desenvolvidos a partir do trabalho de Sasaki (1958). A ideia básica consiste em minimizar uma função custo, diretamente proporcional aos erros de observação e das estimativas dos modelos. A versão tridimensional do método que ele introduziu passou a ser conhecida como Método Variacional Tridimensional (3DVAR). Ressalta-se que as primeiras aplicações desse método na meteorologia foram realizadas no European Centre for Medium-Range Weather Forecasts (ECMWF), em meados da década de 1990. Desde então, o método vem sendo amplamente estudado, desenvolvido e aplicado, tanto nas pesquisas como nas operações dos modelos de previsão numérica do tempo (Kalnay, 2003).

Lorenc (1986), analisando os aspectos probabilísticos da assimilação variacional proposta por Sasaki (1958), concluiu que como a função densidade de probabilidade do erro do background e a função dos erros da observação são gaussianas - a função custo deveria ser um funcional quadrático, isto com base na teoria das probabilidades bayesiana. A partir das considerações estatísticas feitas por ele, os pesquisadores da área passaram a implementar, numericamente, o método 3DVAR em sistemas de Previsão Numérica do Tempo (PNT). Andersson et al. (1995/1996) foram os que apresentaram as características principais do sistema 3DVAR, que começou a ser utilizado a partir de 1996 no ECMWF. Esse novo sistema substituiu aquele que era baseado na IO - que é uma generalização do Método dos Mínimos Quadrados para campos vetoriais que vinha sendo utilizado operacionalmente desde 1979. Andersson et al. (1998) apresentaram os resultados de experimentos realizados no ECMWF e 
concluíram que o método 3DVAR produziu impacto positivo, na previsão de vento e na temperatura sobre a troposfera extratropical do Hemisfério Norte $(\mathrm{HN})$, bem como na análise do campo de vento na superfície do oceano, particularmente na vizinhança de tempestades tropicais. Os avanços proporcionados pela utilização do método 3DVAR no sistema previsor do ECMWF, incentivou outros centros de pesquisa a testar o método, tanto para modelos globais como regionais. Barker et al. (2004), por exemplo, implementaram o método 3DVAR no modelo regional MM5, relatando melhora significativa na previsão da magnitude do vento e uma pequena melhora na previsão de temperatura e umidade relativa.

Nos últimos anos, diversas pesquisas envolvendo assimilação dados no modelo WRF vêm sendo feitas, particularmente utilizando o método 3DVAR (WRF-3DVAR). Sugimoto et al. (2009) assimilaram dados de radar utilizando o sistema WRF-3DVAR doravante chamado de WRF3, e apresentaram resultados com melhora na previsão de curto prazo, tanto da refletividade como velocidade radial do vento - que são importantes para a análise do campo convectivo e por conseguinte para a previsão da precipitação. Rakesh, Singh e Joshi (2009), avaliaram o impacto do método 3DVAR na assimilação de dados de satélite utilizando os modelos WRF e MM5 sobre a Índia. Eles observaram impacto semelhante nos dois modelos, com melhora na condição inicial para os campos de vento, temperatura e umidade. Além desses trabalhos ressaltam-se, dentre outros, o de Routray et al. (2010), que investigaram o impacto da assimilação através do método 3DVAR aplicado ao modelo WRF para eventos de precipitação intensa, ocorridos na região das monções indianas. Eles relataram que o WRF3 foi eficiente tanto na reprodução como na localização e na quantidade prevista de precipitação. Barker et al. (2012) apresentaram os principais avanços obtidos com a utilização dos métodos variacionais em modelos de PNT. Eles revisaram os principais trabalhos na área nos últimos anos e destacaram o surgimento dos métodos híbridos ensemble/variacionais, a criação dos sistemas de assimilação de dados para os modelos WRF e MM5, bem como o aperfeiçoamento das técnicas de assimilação de dados de satélite e radar, e o surgimento e implementação do Método Variacional Quadridimensional (4DVAR), descritos por Zou et al. (2000) e Huang et al. (2009), dentre outros.

Estudos de precipitação na região de interesse, sul do RS, realizados por G. Silva, A. Silva e Yamasaki (2012), com método 3DVAR implementado no modelo MM5, mostram bons resultados obtidos através $\mathrm{da}$ assimilação de refletividade de um radar Doppler.

A avaliação do processo de assimilação de dados 3DVAR utilizando o WRF é explorada neste trabalho e analisada como foco em alguns casos de precipitação ocorridos na Região Sul do Brasil. Os resultados produzidos pelo modelo WRF com a assimilação de dados das estações automáticas de superfície do INMET e de radiossondagem da Região Sul do Brasil, são abordados e apresentados. Dentre os principais focos explorados destaca-se a previsão de precipitação e a estrutura térmica vertical de temperatura do ar, bem como do ponto de orvalho produzidos pelo sistema WRF3. A análise de dois casos de precipitação, ocorridos no ano de 2012 na Região Sul do Brasil e selecionados para a apresentação, foi procedida avaliando-se os prognósticos do WRF, com e sem assimilação de dados. É também explorado o efeito da assimilação de dados de fontes adicionais além dos dados de superfície e radiossonda sobre os prognósticos numéricos, ao se incluir um sub-domínio com maior resolução espacial no modelo.

\section{METODOLOGIA}

A integração do modelo WRF é feita sobre a Região Sul do Brasil englobando, em particular, os estados do Paraná (PR), Santa Catarina (SC) e Rio Grande do Sul (RS). O modelo foi configurado em projeção 
cartográfica Lambert, com espaçamento horizontal entre os pontos de grade de $18 \mathrm{~km}$ e com 35 níveis $\eta$ na vertical. As condições iniciais e de fronteira são fornecidas pelo modelo global GFS.

Os eventos selecionados para apresentação compreendem dois casos de precipitação ocorridos na Região Sul do Brasil, que foram causados por uma ciclogênese associada à uma frente fria com forte baroclinia. O primeiro caso gerou grandes volumes de precipitação acumulada, associada à ciclogênese do dia 18 de setembro de 2012 e oclusão no dia seguinte (caso 1). O segundo caso também causou precipitação e apresentou uma ciclogênese no dia 22 de novembro de 2012 e oclusão no dia 24 (caso 2).

As parametrizações utilizadas no processamento do WRF foram: esquema de microfísica de Goddard; esquema Rapid Radiative Transfer Model (RRTM) para radiação de onda longa; esquema de Dudhia para radiação de onda curta; esquema de camada superficial PBL de Nakanishi e Niino; esquema de superfície de difusão termal de 5 camadas; esquema de camada limite planetária de Mellor-Yamada Nakanishi e Niino e esquema de Kain-Fritsch para parametrização cumulus. Essas parametrizações são descritas em detalhes por Wang et al. (2012).
Os dados assimilados foram provenientes dos registros das estações automáticas do Instituto Nacional de Meteorologia (INMET, 2012), e dados convencionais de superfície e radiossondagem obtidos pelo sistema Local Data Manager (LDM).

Os locais dos pontos de coleta dos dados utilizados no processamento das assimilações são apresentados nas Figuras 1 e 2, plotadas utilizando o sistema NCL/NCAR. No domínio analisado, há 82 estações de superfície do INMET em operação e 6 estações de radiossondagem. As estações de radiossondagens estão localizadas nas cidades de Foz do Iguaçu, Curitiba, Florianópolis, Porto Alegre, Santa Maria e Uruguaiana. Muito embora haja muitos pontos de coleta dentro do domínio de integração, nem todos os dados coletados nesses locais estavam disponíveis para assimilação pelo WRF3. Na simulação do primeiro caso foram utilizados dados coletados por 73 estações remotas de superfície e de radiossondagem - Curitiba, Foz do Iguaçu e Porto Alegre. No segundo caso foram utilizados dados coletados por 74 estações remotas de superfície do INMET e 5 de radiossondagem. A radiossondagem de Santa Maria apresentava poucos níveis de dados e não passou pelo controle de qualidade.

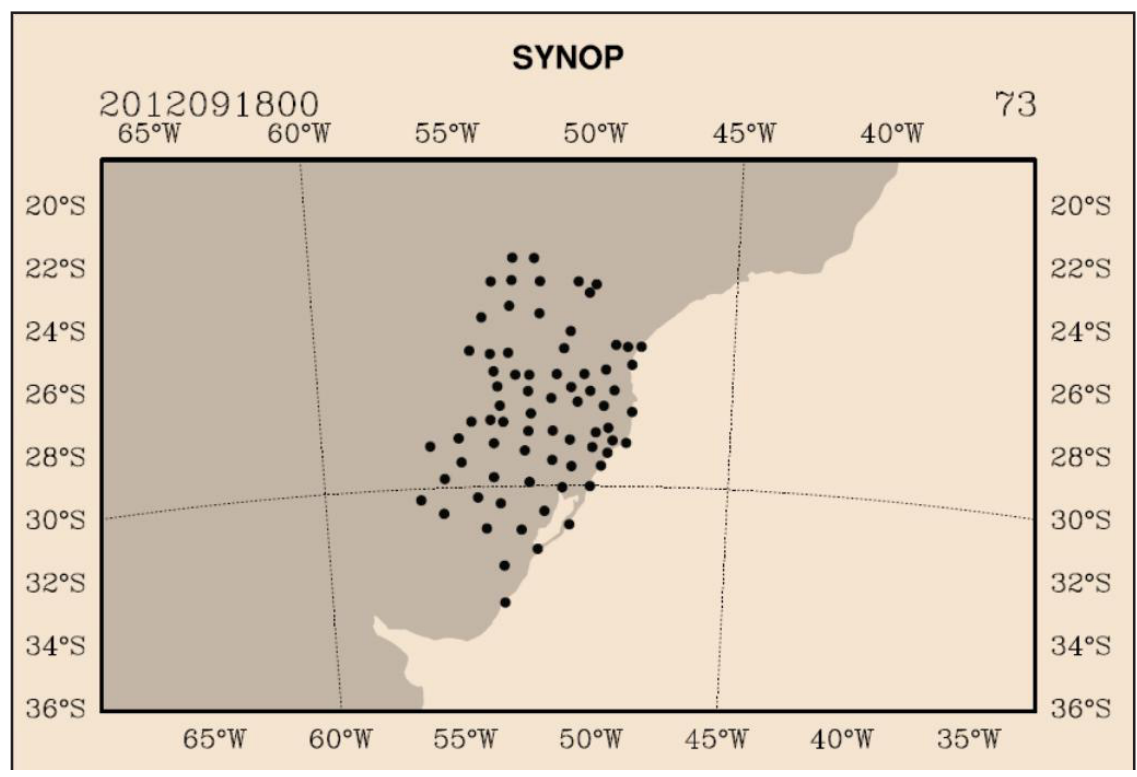

Figura 1 - Locais das Coleta de Dados de Superfície do Caso 1 


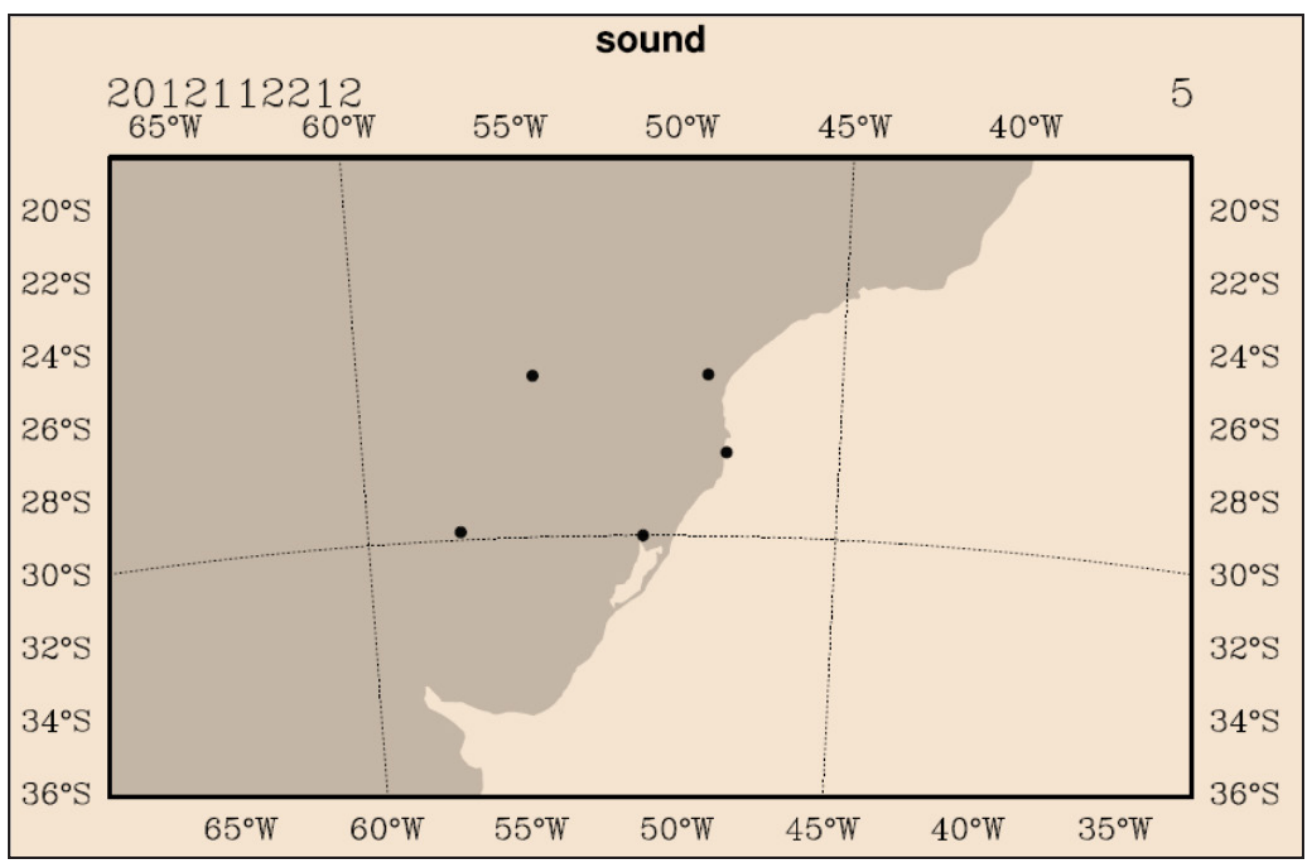

Figura 2 - Locais das Coletas de Dados de Radiossondagen do Caso 2

Para se proceder a assimilação, os dados foram transformados para o formato LITTLE_R (WANG et. al., 2012), requerido pelo WRF3. É importante ressaltar que os dados das estações automáticas do INMET não vêm sendo assimilados, de forma operacional pelo GFS, visto não serem disponibilizados no circuito do Global Telecomunication System/World Meteorological Organization (GTS/WMO). Assim, a condição inicial gerada para o processamento do WRF3 agrega informações que não estão contidas na condição inicial fornecida pelo modelo global GFS e um novo arquivo de análise, com assimilação, é preparado para o processamento do modelo. Além disso, ainda que os dados de radiossondagem já estejam sendo assimilados pelo GFS - tendo em vista que o processamento do WRF3 é realizado com uma resolução espacial maior que a do GFS, que apresenta uma distância entre os pontos de grade da ordem de $50 \mathrm{~km}$, bem maior que a dos $18 \mathrm{~km}$ do WRF3 - a assimilação dos dados produz diferentes condições iniciais na análise.

O cenário sinótico dos casos de precipitação é descrito baseado no produto
INPE/CPTEC/GPT, não apresentados em sua totalidade neste texto por razões de espaço, mas disponíveis em CPTEC (2014), imagens do canal infravermelho realçado do satélite GOES-12 (GOES, 2012) e dados das estações automáticas da rede de superfície do INMET (INMET, 2012). Os campos do modelo analisados na verificação foram: Precipitação Horária (PREC1H), Precipitação Acumulada em 6 Horas (PREC6H) e Precipitação Acumulada em 12 Horas (PREC12H). Os dados pluviométricos coletados pelas estações automáticas da rede de superfície do INMET (INMET, 2012) foram utilizados para se realizar a análise da Precipitação Acumulada em 12 Horas (PREC12H). A análise foi feita comparando-se os valores previstos pelo modelo com e sem a assimilação de dados para as cidades de Porto Alegre, Santa Maria, Rio Grande, Joaçaba, Florianópolis, Foz do Iguaçu e Curitiba. Também foram avaliados os perfis verticais das temperaturas do ar (TC) e do ponto de orvalho (TD), para as cidades que apresentam radiossondagens disponíveis nos dias da análise. 


\section{RESULTADOS E DISCUSSÃO}

As análises dos resultados dos prognósticos numéricos do WRF, com e sem a assimilação de dados, para os dois eventos de ocorrência de precipitação no RS são apresentados na sequência. Ressalta-se que as plotagens das Figuras foram elaboradas utilizando o sistema GRADS.

\subsection{Caso 1}

O sistema sinótico que causou mudanças significativas no tempo é abordado com base nos prognósticos do modelo GFS. A abordagem é feita analisando a propagação, intensificação e decaimento do sistema sinótico durante 60 horas de integração do modelo.

Na superfície, a análise das 06:00 UTC do dia 18/09/2012 mostra a presença de um sistema frontal estacionário sobre o sul da América do Sul. Esse sistema se encontra associado a um centro de baixa pressão no norte da Argentina. As Linhas de Corrente no nível de $850 \mathrm{hPa}$ mostram que os ventos de noroeste mais intensos deslocam o sistema em direção ao RS. Os prognósticos subsequentes mostram que outra frente se forma no sul do Oceano Pacífico - junto ao litoral leste da América do Sul. Ela é seguida por um anticiclone migratório pós-frontal, com ambos se deslocando para a direção leste. O acoplamento desses sistemas frontais é que causaram, em última instância, as precipitações observadas em Santa Rosa e
Porto Alegre. Mesmo decorridas cerca de 12 horas após a PREC1H observada em Caçapava do Sul e Canguçu. Na tabela 1 são apresentados registros de PREC1H em algumas cidades do RS entre os dias 18 e 19 de setembro de 2012.

Os campos das Linhas de Corrente e da Altura Geopotencial em 500hPa, para 06:00 UTC do dia 18/09/2012, mostram um cavado pronunciado que mantém a atmosfera baroclinicamente instável no RS. À leste deste cavado, região associada a advecção de vorticidade em ondas de escala sinótica em latitudes médias, foram registrados grandes volumes de precipitação. Os campos de Linhas de Corrente e da Altura Geopotencial em $250 \mathrm{hPa}$ mostram a ação do Jato Subtropical e do Jato Polar. A propagação, intensificação e o decaimento destes sistemas foram responsáveis pela precipitação registrada nas estações automáticas de superfície do INMET entre 18 e 19 de setembro de 2012.

As imagens do canal infravermelho, do satélite GOES-12, auxiliaram na localização das áreas com precipitação, bem como na evolução e propagação do sistema convectivo para a direção norte-nordeste da Região Sul do Brasil. A imagem das 12:15 UTC do dia 18/09/2012 (Figura 3) mostra que o sistema convectivo já se encontrava sobre a Região Sul do Brasil. Nas imagens subsequentes foi observado que ele se deslocou de oeste para leste alcançando o norte e o leste do RS por volta das 00:00 UTC do dia 19/09/2012.

Tabela 1 - PREC1H registrada por estações automáticas do INMET no caso 1

\begin{tabular}{|c|c|c|c|}
\hline CIDADE & DATA & HORÁRIO & PREC1H \\
\hline Caçapava do Sul & $18 / 09 / 2012$ & $08: 00$ UTC & $33.8 \mathrm{~mm}$ \\
\hline Canguçu & $18 / 09 / 2012$ & $13: 00$ UTC & $16.8 \mathrm{~mm}$ \\
\hline Santa Rosa & $19 / 09 / 2012$ & $00: 00$ UTC & $32.4 \mathrm{~mm}$ \\
\hline Porto Alegre & $19 / 09 / 2012$ & $02: 00$ UTC & $26.8 \mathrm{~mm}$ \\
\hline
\end{tabular}




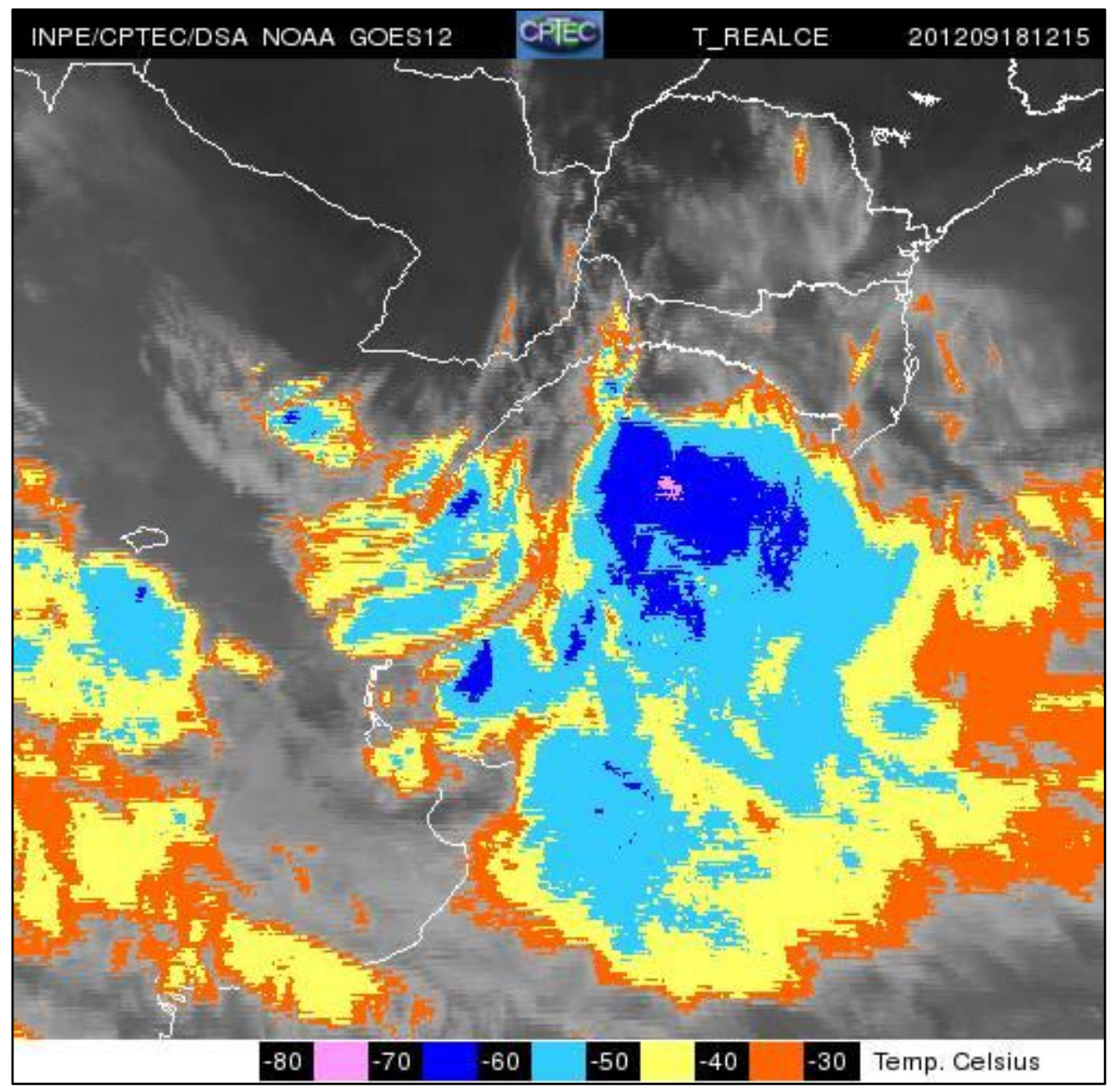

Figura 3 - Imagem de satélite do dia 18/09/2012 às 12:15 UTC.

Fonte: INPE/CPTEC/DSA

De acordo com os dados registrados das precipitações, elas ocorreram em diferentes horas do dia e com intensidades relativamente moderadas. As análises sinóticas realizadas, revelam que o sistema penetrou na Região Sul do Brasil por volta das 06:00 UTC do dia 18/09/2012. Este sistema deslocou-se de oeste para leste no RS e causou precipitação acima de $30 \mathrm{~mm}$ de PREC1H em algumas cidades - como em Caçapava do Sul e Santa Rosa respectivamente às 08:00 UTC e 13:00 UTC de 18/09/2012 (INMET, 2012). A precipitação nestas cidades foi causada pela ciclogênese, associada à formação da frente estacionária, que no dia 19/09/2012 evolui para uma frente fria clássica. A segunda frente, que se formou no Pacífico, deslocou o sistema na direção norte/nordeste, e foi a responsável pela PREC1H registrada em Santa Rosa às 00:00 UTC do dia 19/09/2012, e em Porto
Alegre às 02:00 UTC do mesmo dia (INMET, 2012). O sistema se propagou de oeste para leste segundo uma onda de Rossby, com uma atmosfera com forte instabilidade baroclínica intensificada pelo calor e umidade transportados da Amazônia para a Região Sul do Brasil. Na tabela 2 é apresentada a PREC12H registrada pelas estações do INMET.

O WRF3 subestimou a PREC6H observada na vanguarda da frente e superestimou PREC6H observada na sua retaguarda. Foi observado que às 12:00 UTC do dia 19/09/2012 o sistema frontal já havia se deslocado para o estado de SC, onde causou precipitação mais intensa. Com relação à localização, o campo de PREC6H foi previsto com certo atraso pelo modelo com assimilação, quando comparado com os prognósticos do WRF sem assimilação. 
Tabela 2 - PREC12H registrada por estações do INMET no caso 1

\begin{tabular}{|c|c|c|c|c|c|}
\hline CIDADE & $\begin{array}{c}12: 00 \mathrm{UTC} \\
18 / 092012\end{array}$ & $\begin{array}{c}00: 00 \text { UTC } \\
19 / 092012\end{array}$ & $\begin{array}{c}12: 00 \mathrm{UTC} \\
19 / 092012\end{array}$ & $\begin{array}{c}00: 00 \text { UTC } \\
20 / 092012\end{array}$ & $\begin{array}{c}12: 00 \mathrm{UTC} \\
20 / 09 / 2012\end{array}$ \\
\hline Porto Alegre & $40.6 \mathrm{~mm}$ & $28.2 \mathrm{~mm}$ & $46.6 \mathrm{~mm}$ & $0.2 \mathrm{~mm}$ & $0.0 \mathrm{~mm}$ \\
\hline Santa Maria & $41.8 \mathrm{~mm}$ & $42.4 \mathrm{~mm}$ & $13.2 \mathrm{~mm}$ & $2.0 \mathrm{~mm}$ & $0.0 \mathrm{~mm}$ \\
\hline Rio Grande & $43.4 \mathrm{~mm}$ & $19.8 \mathrm{~mm}$ & $1.2 \mathrm{~mm}$ & $1.2 \mathrm{~mm}$ & $0.0 \mathrm{~mm}$ \\
\hline Joaçaba & $0.0 \mathrm{~mm}$ & $0.0 \mathrm{~mm}$ & $28.2 \mathrm{~mm}$ & $5.2 \mathrm{~mm}$ & $0.0 \mathrm{~mm}$ \\
\hline Florianópolis & $0.0 \mathrm{~mm}$ & $0.0 \mathrm{~mm}$ & $1.2 \mathrm{~mm}$ & $2.2 \mathrm{~mm}$ & $0.0 \mathrm{~mm}$ \\
\hline Foz do Iguaçu & $0.0 \mathrm{~mm}$ & $0.0 \mathrm{~mm}$ & $27.0 \mathrm{~mm}$ & $0.0 \mathrm{~mm}$ & $0.2 \mathrm{~mm}$ \\
\hline Curitiba & $0.0 \mathrm{~mm}$ & $0.0 \mathrm{~mm}$ & $0.0 \mathrm{~mm}$ & $2.6 \mathrm{~mm}$ & $0.0 \mathrm{~mm}$ \\
\hline
\end{tabular}

A dificuldade esperada na previsão da precipitação, constatada pelos valores obtidos da PREC6H, estimulou a investigação da PREC12H. A previsão de PREC12H poderia ter melhor resultado em relação à acumulada em 6 horas, devido ao spin-up problem (Oyama; Rocha; Nobre, 2000) - tempo necessário para o modelo entrar em balanço e gerar precipitação - e ao problema de inicialização - filtragem de oscilações de alta frequência. Este aspecto não foi explorado neste trabalho, embora o modelo tenha a opção de integração com remoção de ondas de gravidade pelo Filtro Digital (Innocentini et al., 2002).

Os valores de PREC12H registrados pelas estações automáticas do INMET norteiam a avaliação, visto que os valores registrados pelo INMET, nas cidades de Porto Alegre, Santa Maria, Rio Grande, Joaçaba, Florianópolis, Foz do Iguaçu e Curitiba, mostraram que as maiores precipitações ocorreram no RS, nas cidades de Porto Alegre, Santa Maria e Rio Grande, entre 00:00 UTC de 18/09/2012 e 12:00 UTC do dia seguinte. Em Joaçaba e Foz do Iguaçu também foram registrados grandes valores de PREC12H, entre 00:00 UTC e 12:00 UTC do dia 19/09/2012 (INMET, 2012). A análise baseada nos prognósticos do GFS, destacaram a formação de uma frente estacionária sobre o RS no dia 18/09/2012, com a apresentação de intensa atividade convectiva às 12:00 UTC no estado. Este sistema causou PREC12H de 40,6 mm em Porto Alegre; 41,8mm em Santa Maria e 43,4mm em Rio Grande (INMET, 2012). Os dois prognósticos do WRF, com e sem assimilação de dados, previram a entrada deste sistema, causando instabilidade e precipitação na metade sul do RS. Eles praticamente não previram precipitação alguma nas áreas da Região Sul do Brasil onde realmente não houve precipitação, segundo os registros do INMET (2012).

No dia 19/09/2012 o sistema evoluiu para uma frente fria clássica. Às 00:00 UTC a frente se deslocou para a metade norte do RS e causou $28,2 \mathrm{~mm}$ de PREC12H em Porto Alegre; 42,4mm em Santa Maria e 19,8 mm em Rio Grande (INMET, 2012). O WRF3 previu com atraso, a propagação do sistema frontal (Figura 4). Às 00:00 UTC do dia 20/09/2012, a frente estava no PR, o que foi melhor representado WRF sem assimilação em relação ao WRF3, tendo em vista o posicionamento do sistema observado nos campos dos prognósticos de PREC12H das duas integrações - respectivamente com e sem assimilação de dados. No entanto, em termos de valores numéricos, os valores de PREC12H dos prognósticos do WRF3 foram menos subestimados do que os do WRF sem assimilação de dados. 


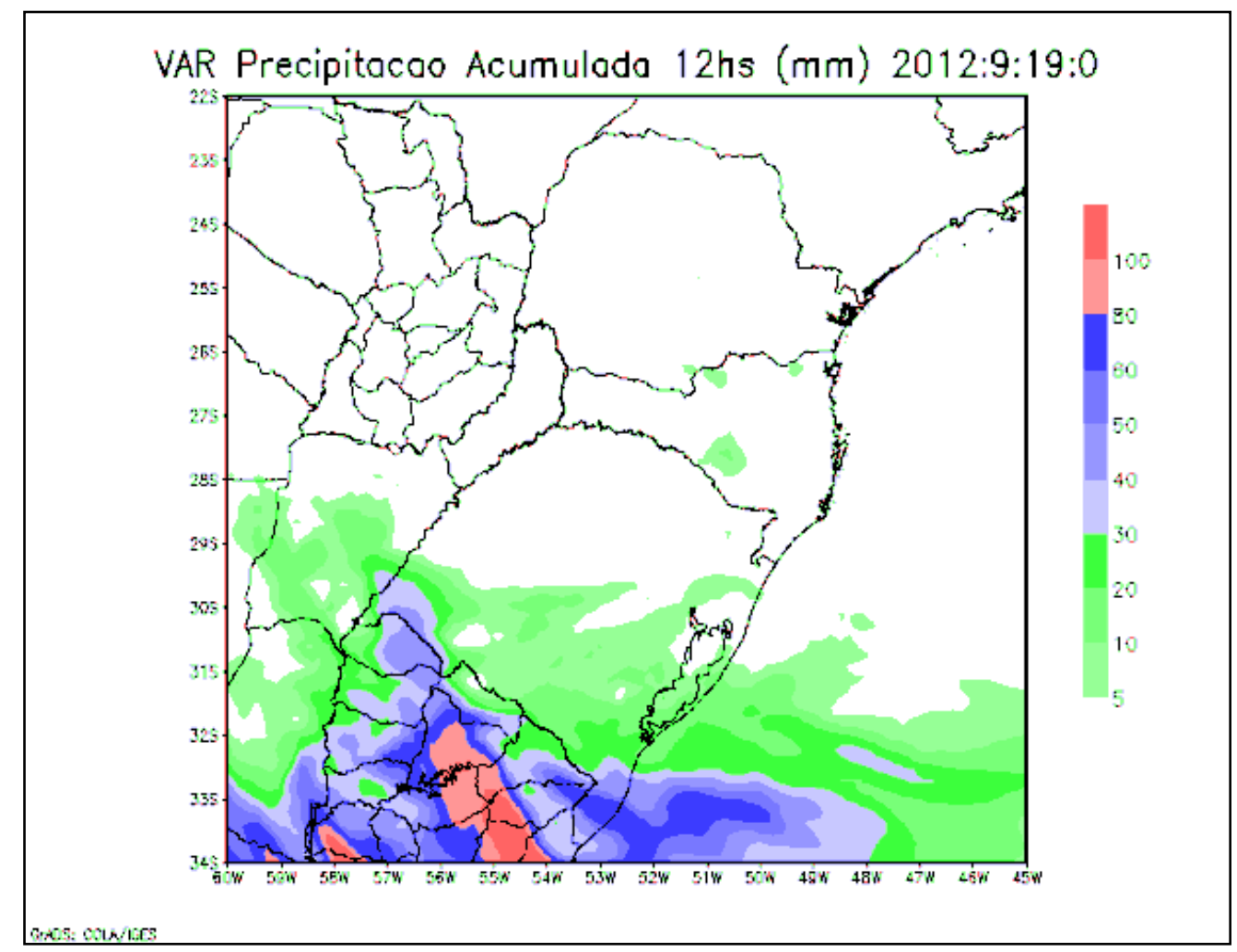

Figura 4 - PREC12H prevista pelo WRF3 às 00:00 UTC do dia 19/09/2012.

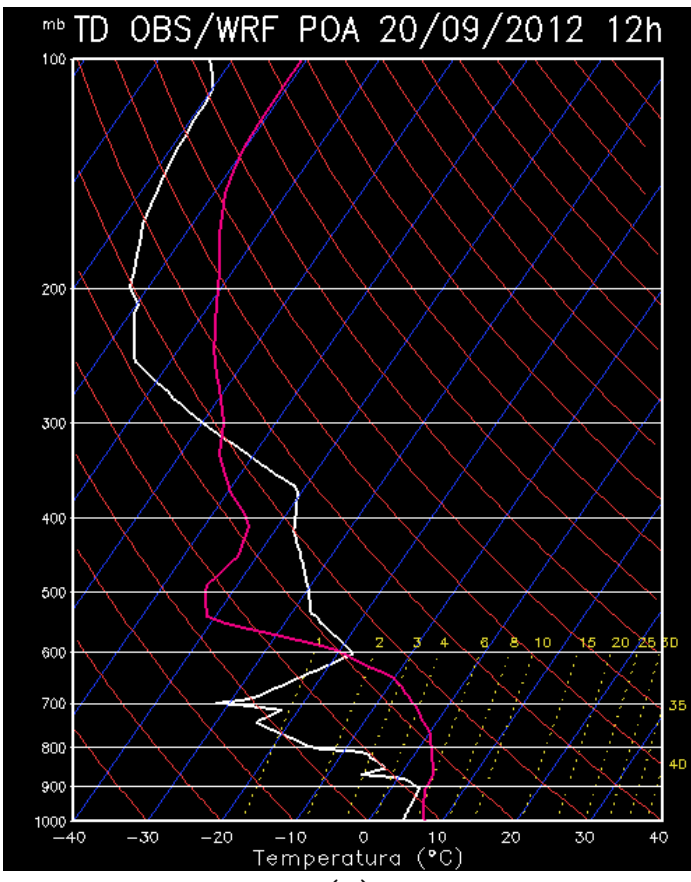

(a)

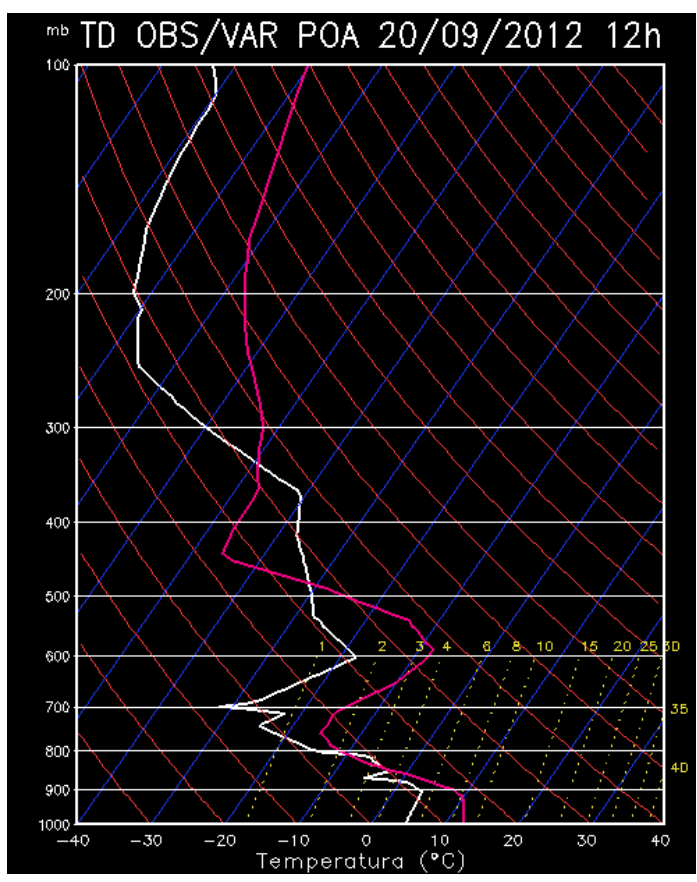

(b)

Figura 5 - Perfil vertical de temperatura do ponto de orvalho em Porto Alegre para 12:00 UTC do dia 20/09/2012 previstos pelo (a) WRF sem assimilação de dados e (b) WRF3 na curva escura, e observado na curva em branco 
Com relação aos perfis verticais de temperatura, o WRF3 apresentou, de uma forma geral, melhor previsão de TC e TD nos altos níveis em Curitiba e da superfície até os níveis médios em Porto Alegre. Em Foz do Iguaçu, a diferença entre a performance do modelo com e sem assimilação foi bastante pequena - sem melhora significativa na representatividade do WRF3 em relação ao WRF sem assimilação; tanto para a TC quanto para a TD. Destaca-se, entretanto, que no caso 1 o WRF3 reproduziu inversões térmicas mais próximas das observadas, comparado com o modelo sem assimilação - ainda que as diferenças entre os perfis de TC e TD proporcionados pelas duas previsões sejam pequenas. Na Figura 5 são apresentados os perfis de TD previstos pelo modelo com e sem assimilação para Porto Alegre, às 12:00 UTC do dia 20/09/2012; juntamente com o perfil observado.

\subsection{Caso 2}

Às 12:00 UTC do dia 22/11/2012, os campos da Pressão Reduzida ao nível do mar e a Temperatura Potencial mostram uma ampla região de baixa pressão sobre o norte da Argentina, conhecida como Baixa do Chaco, associada à uma frente que se desloca para leste. Nas Linhas de Corrente, em 850 $\mathrm{hPa}$, nota-se a predominância dos ventos para o sudeste. No nível de $500 \mathrm{hPa}$, de acordo com as linhas de corrente e Altura Geopotencial, nota-se a presença de um cavado ao sul da América do Sul. À leste deste cavado, estão localizadas as cidades que registraram grandes valores de precipitação. Em $250 \mathrm{hPa}$, o campo de Linhas de Corrente e Altura Geopotencial do GFS, mostra a ação dos Jatos Subtropicais e dos Jatos Polares com estes últimos transportando massas de ar polar em direção ao continente; e escoamentos intensificados pela atuação dos Jatos Subtropicais. Às 12:00 UTC do dia seguinte, os campos da Pressão Reduzida ao nível médio do mar e da Temperatura Potencial apresentam grande redução de Pressão Reduzida e aumento da Temperatura Potencial sobre o RS, principalmente junto à fronteira com o Uruguai. No nível de $500 \mathrm{hPa}$, o eixo do cavado se desloca para leste enquanto outra frente se desloca em direção à Região Sul do Brasil, retratados pelas linhas de corrente e altura Geopotencial.

As imagens das 15:00 UTC do canal infravermelho do satélite GOES-12 do dia 22/11/2012 (Figura 6), apresentaram nuvens com topos altos e frios causando precipitação em alguns municípios do RS, devido ao deslocamento de uma frente estacionária. Elas mostram também que o sistema formou-se rapidamente e se deslocou em direção ao oceano em poucas horas - ciclogênese rápida. Logo após sua formação, o sistema frontal avançou pelo sul da América do Sul, chegando à fronteira entre o Uruguai e o RS às 15:00 UTC, intensificou-se e provocou precipitação intensa ao se deslocar para a direção norte-nordeste. $\mathrm{O}$ sistema avançou para o norte do RS e oeste de SC e PR, e em seguida, entrou em fase de oclusão.

A PREC1H observada em Jaguarão, Rio Grande, São Gabriel e Santa Maria (tabela 3) mostra que, conforme as análises realizadas, o sistema sinótico penetrou na Região Sul do Brasil, por volta das 17:00 UTC de 22/11/2012. Ele se deslocou rapidamente, de oeste para leste sobre o estado do RS, causando precipitação em Jaguarão, Rio Grande e São Gabriel. A segunda frente que transportou umidade do Oceano Pacífico na direção da Região Sul do Brasil, causou pouca precipitação no centro do RS. Na imagem do infravermelho do satélite GOES-12 das 00:15 UTC do dia 24/11/2012 ainda foi possível notar um pequeno núcleo de nebulosidade na região próxima à Santa Maria.

Muito embora não tenha ocorrido precipitação tão intensa quanto a do caso anterior, o segundo caso é interessante para o estudo do desempenho do WRF3 aplicado à ciclogêneses rápidas (RABIER et al., 1998). 


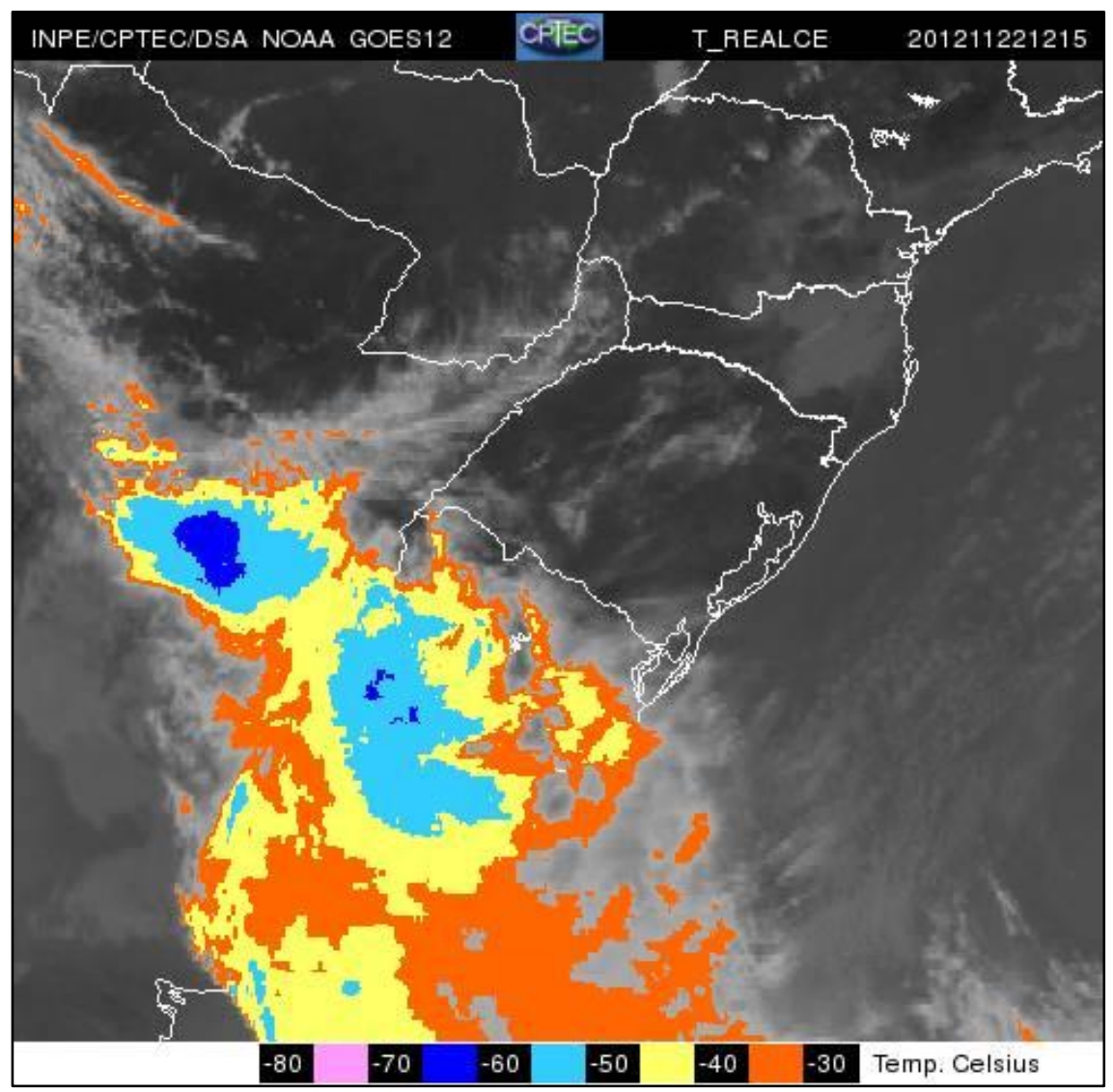

Figura 6 - Imagens de satélite do dia 22/11/2012 às 12:05 UTC. Fonte: INPE/CPTEC/DAS

Tabela 3 - PREC1H registrada por estações automáticas do INMET no caso 2

\begin{tabular}{|c|c|c|c|}
\hline CIDADE & DATA & HORÁRIO & PREC1H \\
\hline Jaguarão & $22 / 11 / 2012$ & $21: 00 \mathrm{UTC}$ & $18.9 \mathrm{~mm}$ \\
\hline Rio Grande & $23 / 11 / 2012$ & $00: 00 \mathrm{UTC}$ & $18.0 \mathrm{~mm}$ \\
\hline São Gabriel & $23 / 11 / 2012$ & $01: 00 \mathrm{UTC}$ & $16.8 \mathrm{~mm}$ \\
\hline Santa Maria & $23 / 11 / 2012$ & $21: 00 \mathrm{UTC}$ & $18.4 \mathrm{~mm}$ \\
\hline
\end{tabular}

Conforme descrito, o WRF3 previu menos PREC6H que o WRF sem assimilação, de forma mais coerente com o observado nos dados do INMET (2012), bem como a posição do sistema frontal está mais coerente com as imagens do GOES-12. Ainda que a PREC6H, tenha sido mais aproximada aos valores observados, eventualmente resultante do problema de inicialização, as análises revelaram também que a previsão de PREC12H é mais precisa que a PREC6H, como no caso anterior.
As previsões da PREC12H com e sem assimilação foram comparadas com os valores registrados nas estações automáticas do INMET. A PREC12H registrada pelo INMET nas cidades de Porto Alegre, Santa Maria, Rio Grande, Joaçaba, Florianópolis, Foz do Iguaçu e Curitiba indica que a maior parte da precipitação ocorreu em Santa Maria e Foz do Iguaçu, entre 12:00 UTC de 23/11/2012 e 00:00 UTC de 24/11/2012, conforme apresentado na tabela 4 . 
Tabela 4 - PREC12H registrada por estações do INMET no caso 2

\begin{tabular}{|c|c|c|c|c|}
\hline CIDADE & $\begin{array}{c}00: 00 \text { UTC } \\
23 / 112012\end{array}$ & $\begin{array}{c}12: 00 \text { UTC } \\
23 / 112012\end{array}$ & $\begin{array}{c}00: 00 \text { UTC } \\
24 / 11 / 2012\end{array}$ & $\begin{array}{c}12: 00 \text { UTC } \\
24 / 11 / 2012\end{array}$ \\
\hline Porto Alegre & $0.0 \mathrm{~mm}$ & $4.2 \mathrm{~mm}$ & $0.0 \mathrm{~mm}$ & $9.2 \mathrm{~mm}$ \\
\hline Santa Maria & $4.0 \mathrm{~mm}$ & $11.4 \mathrm{~mm}$ & $36.8 \mathrm{~mm}$ & $0.8 \mathrm{~mm}$ \\
\hline Rio Grande & $18.0 \mathrm{~mm}$ & $3.8 \mathrm{~mm}$ & $0.0 \mathrm{~mm}$ & $0.0 \mathrm{~mm}$ \\
\hline Joaçaba & $5.8 \mathrm{~mm}$ & $0.0 \mathrm{~mm}$ & $2.2 \mathrm{~mm}$ & $0.6 \mathrm{~mm}$ \\
\hline Florianópolis & $0.0 \mathrm{~mm}$ & falha & $1.6 \mathrm{~mm}$ & falha \\
\hline Foz do Iguaçu & $0.0 \mathrm{~mm}$ & $37.8 \mathrm{~mm}$ & $40.2 \mathrm{~mm}$ & $0.0 \mathrm{~mm}$ \\
\hline Curitiba & $0.0 \mathrm{~mm}$ & $0.0 \mathrm{~mm}$ & $0.0 \mathrm{~mm}$ & $1.4 \mathrm{~mm}$ \\
\hline
\end{tabular}

A imagem do infravermelho do satélite GOES-12 das 15:00 UTC do dia 22/11/2012 apresenta uma frente fria no norte da Região Sul do Brasil, com o centro de baixa pressão sobre o Oceano Atlântico Sul. No campo de Pressão Reduzida ao nível do mar, apresentado pelos prognósticos do modelo GFS, além da Baixa do Chaco, bem definida na Argentina, observa-se uma tendência de baixa pressão na Região Sul do Brasil - com um cavado pronunciado em altos níveis, e escoamento de norte em $850 \mathrm{hPa}$. Estes campos mostram, também, a entrada de um sistema frontal pelo Uruguai, que no dia 23/11/2012, desloca-se de oeste para leste, reduzindo a pressão sobre a Região Sul do Brasil. Observa-se também uma inclinação do eixo do cavado, evidenciando a baroclinia do sistema. Estas observações foram resumidas, para destacar a forte instabilidade em toda Região Sul do Brasil no período compreendido entre 22 e 23 de novembro de 2012, confirmada pela Temperatura do Ponto de Orvalho, que se apresentava bastante alta nas cidades analisadas. Portanto, esperava-se que o campo de PREC12H do modelo reproduzisse este cenário, pelo menos sob o ponto de vista qualitativo.

Os campos de PREC12H foram previstos de forma bem distinta. Enquanto o WRF sem assimilação gerou precipitação, associada à entrada do sistema sobre o Uruguai, o WRF3 apresentou precipitação associada com o sistema posicionado ao norte da Região Sul do Brasil. Observa-se que a previsão do WRF sem assimilação propagou o sistema na direção sudoeste-nordeste. O campo de PREC12H do WRF3, mostrou que a frente se propagando para o norte diminuiu sua influência sobre a Região Sul do Brasil. Apenas no dia 24/11/2012 a PREC12H, do WRF sem assimilação e pelo WRF3 passam a prever precipitação associada ao mesmo sistema frontal.

Conforme esperado, os valores pontuais de PREC12H não foram reproduzidos, nem pelo WRF sem assimilação, nem pelo WRF3. Isso porque os $18,0 \mathrm{~mm}$ registrados em Rio Grande no dia 23/11/2012 às 00:00 UTC (tabela 4), não aparecem em nenhum dos prognósticos. Entretanto, como a PREC12H, com maior valor de PREC12H, de $37,8 \mathrm{~mm}$ do dia 23/11/2012, registrada às 12:00 UTC em Foz do Iguaçu, está associada à frente mais ao norte, foi melhor reproduzida pelo WRF3 (Figura 7).

No dia 24/11/2012, as PREC12H's às 00:00 UTC, foram respectivamente $36,8 \mathrm{~mm}$ e 40,2 mm em Santa Maria e Foz do Iguaçu. O WRF3 previu núcleos de precipitação no centro do RS e pouca precipitação esparsa em algumas áreas do PR (Figura 8). De acordo com a análise dos campos de precipitação realizada, a PREC12H das 00:00 UTC do dia 24/11/2012 foi quantitativamente melhor prevista pelo WRF3, em relação ao WRF sem assimilação. Entretanto, os valores previstos foram superestimados, tanto pelo WRF, quanto pelo WRF3, para SC em 24/11/2013 às 12:00 UTC 


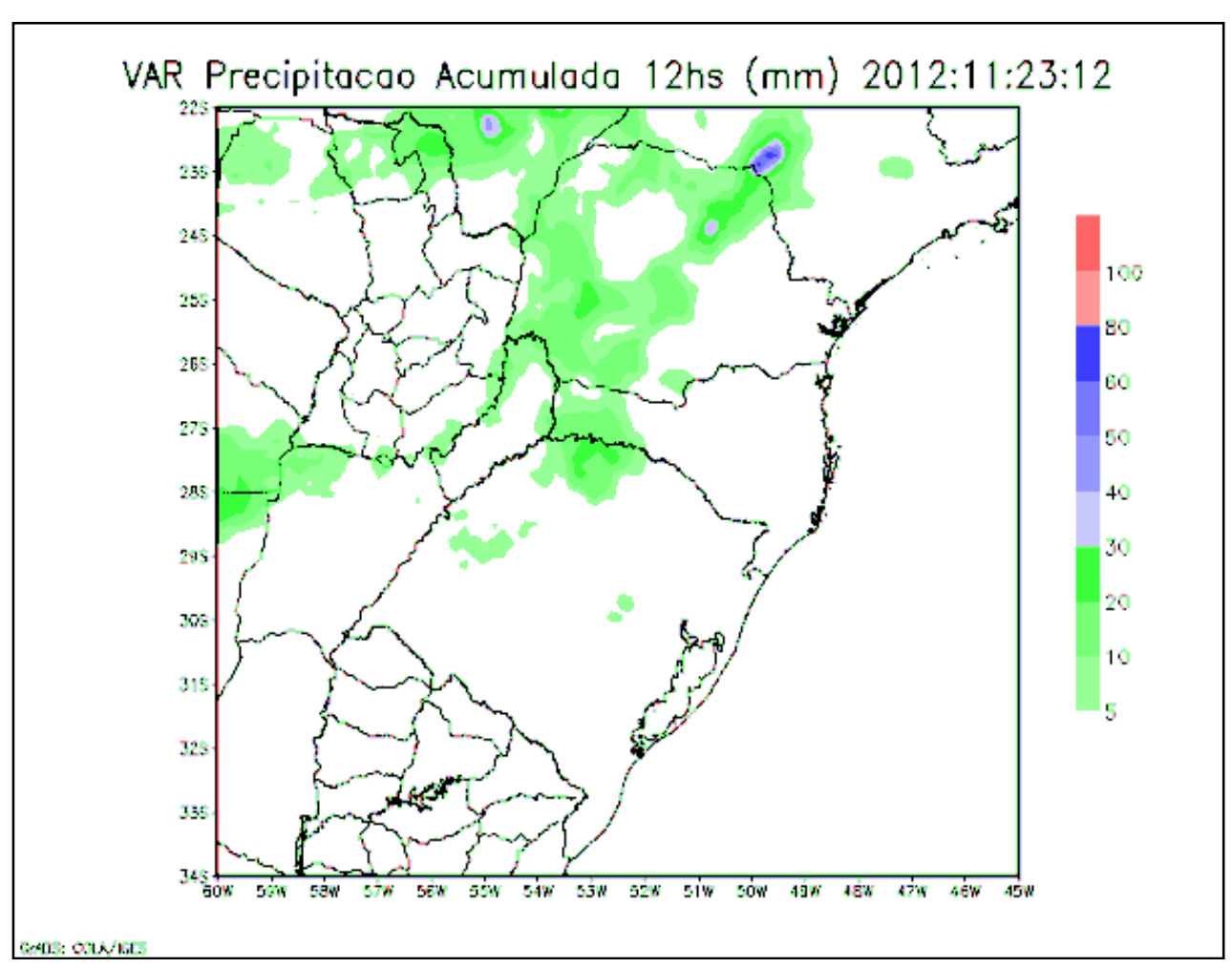

Figura 7 - PREC12H prevista pelo WRF3 às 12:00 UTC do dia 23/11/2012

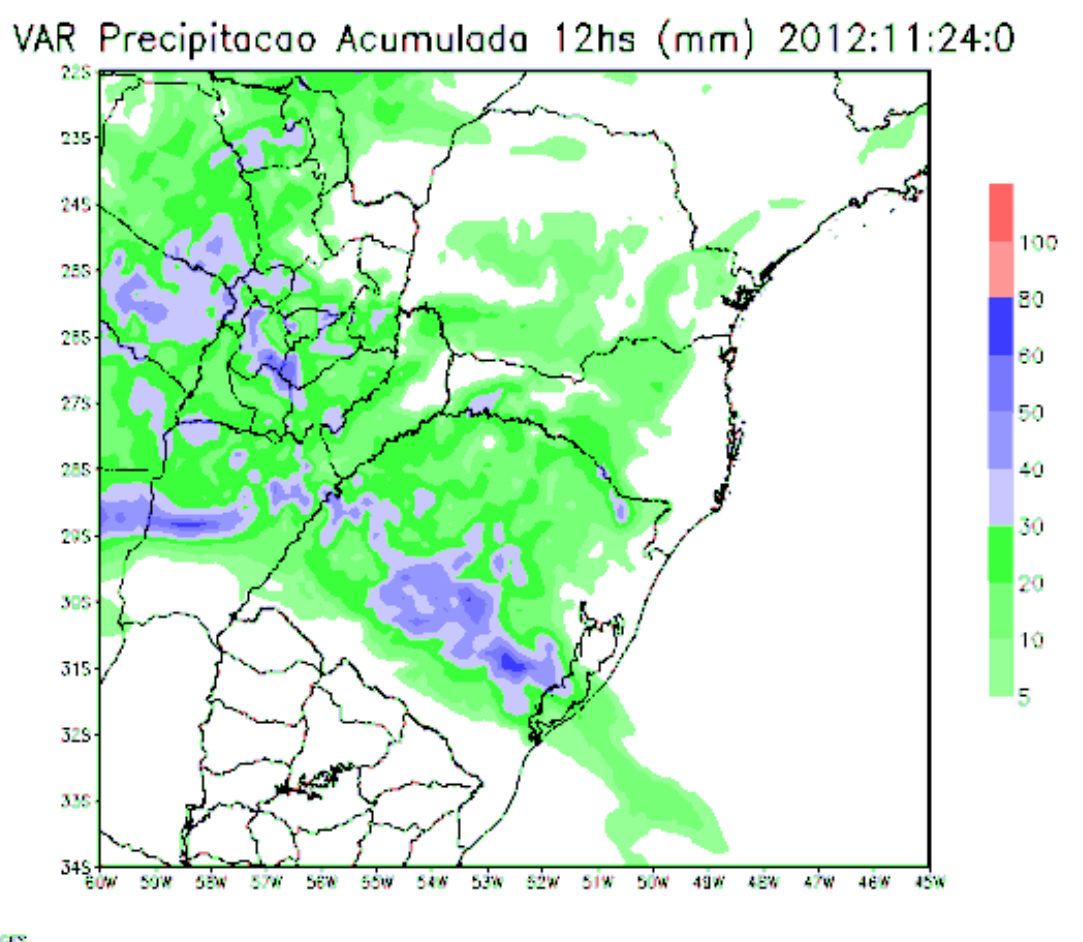

Figura 8 - PREC12H prevista pelo WRF3 às 00:00 UTC do dia 24/11/2012 
Com o objetivo de avaliar e comparar o procedimento da assimilação de dados de superfície e de radiossondagem, com dados provenientes de outras fontes, processou-se o WRF3 com assimilação de 144 dados SYNOP, 77 dados METAR, 8 dados SHIP e 2 dados BUOY. Isto foi feito incorporando um novo domínio, ou seja, utilizou-se um domínio maior, com resolução de $18 \mathrm{~km}$ abrangendo toda a Região Sul do Brasil, e um domínio menor, com resolução de $6 \mathrm{~km}$ abrangendo apenas o RS.

A PREC12H na região próxima à Rio Grande às 00:00 UTC do dia 23/11/2012 não foi prevista, mesmo com a assimilação de dados adicionais e a alta resolução espacial. Na previsão das 12:00 UTC do dia 23/11/2012, o WRF3 com assimilação de dados adicionais, não previu precipitação nas proximidades da cidade de Santa Maria, conforme descrito anteriormente apenas com dados de superfície e radiossondagem.

Às 00:00 UTC do dia 24/11/2012, o

WRF3 com assimilação de dados adicionais reproduziu o cenário de PREC12H observado na região próxima à Santa Maria. Nota-se que valores próximos de $36,8 \mathrm{~mm}$ foram registrados nas proximidades desta cidade, e observa-se, no domínio que abrange apenas o RS, um núcleo de precipitação bem definido, que ultrapassa 40,0mm; isto é, uma previsão mais detalhada foi obtida com o aumento da resolução espacial, em concordância com os valores observados, e com as imagens do satélite GOES-12 das 00:15 UTC de $24 / 11 / 2012$.

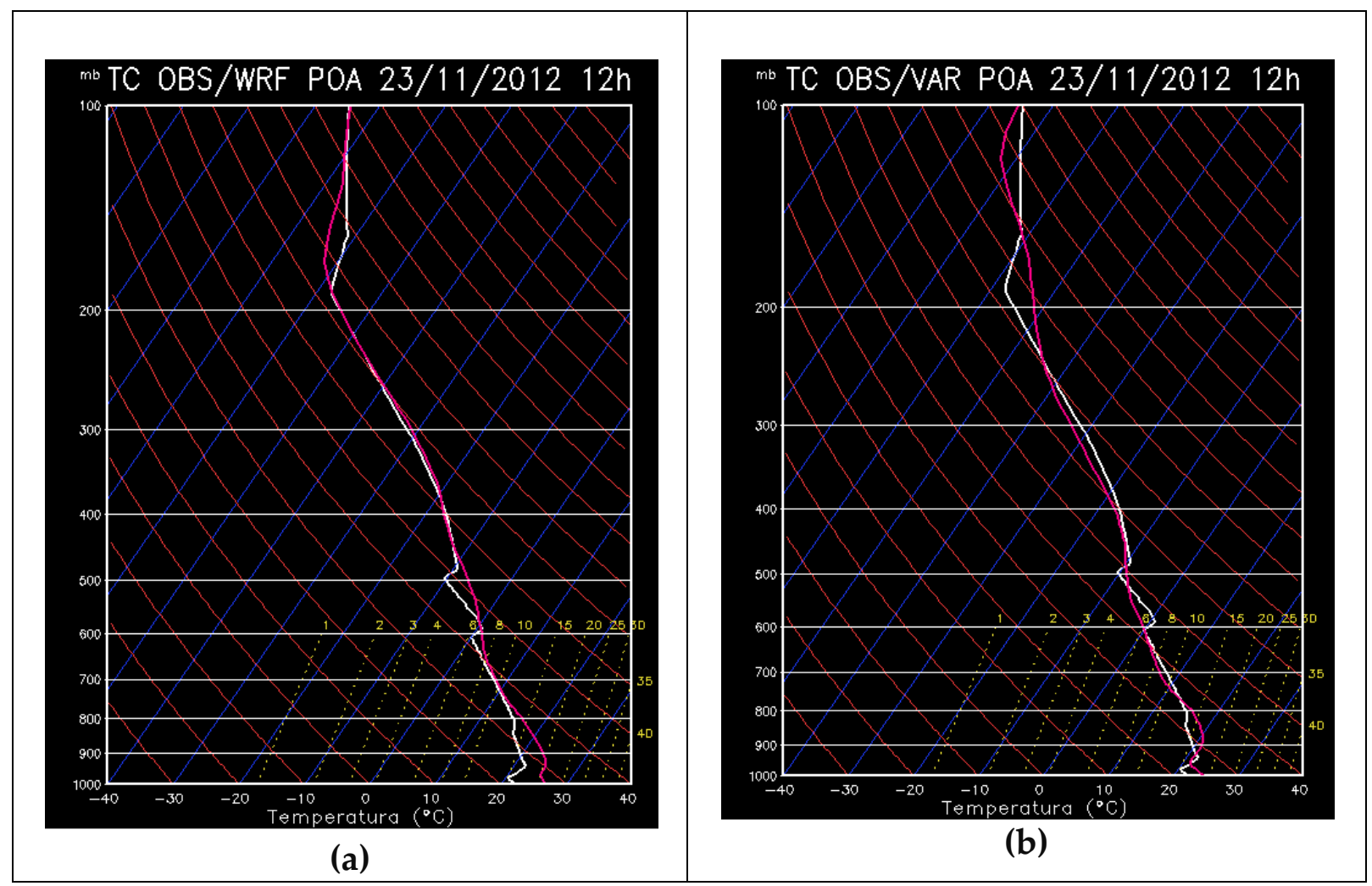

Figura 9 - Perfil vertical de temperatura do ponto de orvalho em Porto Alegre para 12:00 UTC do dia 23/11/2012 previstos pelo (a) WRF sem assimilação de dados e (b) WRF-3DVAR na curva escura, e observado na curva em branco

Com a assimilação dos dados adicionais, houve um aumento dos valores de PREC12H previstos na região próxima à Foz do Iguaçu, onde foram registrados grandes valores de PREC12H. Ressalta-se ainda, que a precipitação localizada em algumas cidades do RS, na fronteira com o Uruguai - previsão das 12:00 UTC do dia 23/11/2012, os núcleos 
de precipitação sobre o Uruguai - previsão das 18:00 UTC do dia 23/11/2012, e o núcleo de precipitação em Santa Maria - previsão das 00:00 UTC do dia 24/11/2012; foram melhor representados no experimento com alta resolução espacial.

Com relação aos perfis verticais de temperatura, o WRF3 melhorou sensivelmente a previsão do perfil tanto da TC quanto da TD em relação ao WRF sem assimilação, até o nível de $500 \mathrm{hPa}$, para as cidades de Curitiba, Foz do Iguaçu e Florianópolis, e obteve um perfil de TC mais aproximado ao observado nos níveis próximos à superfície em Porto Alegre. Ressalta-se que no caso 2, a assimilação de dados proporcionou melhora significativa na simulação das inversões térmicas, sobretudo próximo à superfície. A Figura 9 mostra, os perfis de TC previstos pelo WRF3 e pelo WRF sem assimilação para Porto Alegre às 12:00 UTC de 23/11/2012, bem como $o$ perfil da radiossondagem no mesmo horário.

\section{CONCLUSÃO}

De acordo com a análise do Caso 1, concluí-se que tanto o WRF sem assimilação quanto o WRF3 praticamente não mostraram PREC12H nas áreas da Região Sul do Brasil onde não houve precipitação, segundo os registros do INMET. Também concluí-se que o WRF3 previu com atraso a propagação do sistema neste caso. Às 00:00 UTC do dia 20/09/2012, a frente estava no Paraná, o que foi melhor representado pelo WRF sem assimilação.

No caso 2, como esperado, valores pontuais de PREC12H não foram reproduzidos, nem pelo WRF sem assimilação, nem pelo WRF3, haja vista que os $18,0 \mathrm{~mm}$ registrados em Rio Grande às 00:00 UTC do dia 23/11/2012, não aparecem nos campos previstos. Como a PREC12H de 37,8 $\mathrm{mm}$ do dia 23/11/2012, registrada às 12:00 UTC em Foz do Iguaçu, está associada à frente mais ao norte, logo, foi melhor reproduzida pelo WRF3. Às 00:00 UTC do dia 24/11/2012, foram registrados respectivamente $36,8 \mathrm{~mm}$ e 40,2 mm em Santa Maria e Foz do Iguaçu, sendo que o WRF3 previu núcleos de precipitação no centro do RS e precipitação no oeste do PR. A PREC12H das 00:00 UTC do dia 24 de novembro foi quantitativamente melhor prevista pelo WRF3 do que pelo WRF sem assimilação. Entretanto, os valores previstos, tanto pelo WRF sem assimilação, quanto pelo WRF3, para SC às 12:00 UTC de 24/11/2012 aparecem superestimados em relação aos valores observados.

Os resultados obtidos para eventos de precipitação ocorridos em setembro e novembro de 2012 sobre a Região Sul do Brasil mostraram, de forma geral, a grande importância da assimilação de dados no modelo WRF, na melhora da destreza, em especial na precipitação acumulada em 12 horas. Além disso, constatou-se que essa importância é realçada, ainda mais, ao incluir grades com maior resolução no modelo - no caso, grade com espaçamento de $6 \mathrm{~km}-\mathrm{e}$ dados assimilados de outras fontes, além das estações de superfície e de radiossondagem.

Com o intuito de avaliar a melhora da condição inicial do WRF3 em relação ao WRF sem assimilação, foram calculadas as diferenças entre a análise do WRF3 e o firstguess do WRF sem assimilação de dados. Deste experimento, concluí-se que para os casos estudados, houve a tendência do WRF3 de atrasar a entrada dos sistemas frontais, pois o WRF sem assimilação previu, na região de entrada das frentes, valores mais altos de intensidade das componentes do vento antes do WRF3. Isto foi constatado para a componente zonal em baixos e médios níveis, uma vez que as diferenças na componente meridional foram pequenas, principalmente na atmosfera superior, o que está de acordo com os dados observados. O campo de Temperatura Potencial Perturbada foi analisado e também evidencia que a advecção quente foi antecipada pelo WRF sem assimilação, principalmente em baixos níveis. Considerando que os dados das estações automáticas do INMET são dados de superfície, este resultado está consistente e vai ao encontro do esperado, uma vez que o impacto da assimilação teve maior intensidade em baixos níveis. Estas conclusões 
são válidas para os dois casos, sendo que os gradientes de temperatura são maiores no Caso 2.

Concluí-se que o WRF3 previu perfis verticais de TC e TD bastantes próximos dos observados e com previsões melhores que as do WRF sem assimilação - em Curitiba acima de 200 hPa, e em Porto Alegre até 500 hPa no Caso 1; em Curitiba, Foz do Iguaçu e Florianópolis até $500 \mathrm{hPa}$, e em Porto Alegre próximo à superfície no Caso 2. Destaca-se, entretanto, que no caso 1 o WRF3 reproduziu inversões térmicas mais próximas das observadas, comparado com o modelo sem assimilação.

Os prognósticos dos perfis verticais, tanto da temperatura do ar como da temperatura do ponto de orvalho, para locais onde são lançadas radiossondagens, mostraram, nos prognósticos numéricos, que a assimilação de dados produziu estruturas térmicas e úmidas na vertical de forma mais realística à luz das observações. Como consequência da melhor caracterização dos parâmetros meteorológicos, o modelo WRF apresentou melhores prognósticos numéricos dos perfis analisados quando processado com assimilação de dados, sobretudo com aumento da resolução espacial - no caso 2 .

\section{AGRADECIMENTO}

Os autores agradecem à agência de fomento à pesquisa CAPES, pelo suporte financeiro, bem como ao INMET, por ter proporcionado acesso aos dados das estações remotas, ao INPE, e a todas as outras instituições que, de uma forma ou outra, possibilitaram a realização do trabalho.

\section{REFERÊNCIAS}

ANDERSSON, E.; COURTIER, P.; GAFFARD, C.; HASELER, J.; RABIER, F.; UNDÉN, P.; VASILJEVIC, D. 3D-VAR - THE NEW OPERATIONAL ANALYSIS SCHEME. ECMWF NEWSLETTER, N. 71, P. 2-5, 1995/1996
ANDERSSON, E.; HASELER, J.; UNDÉN, P.; COURTIER, P.; KELLY, G.; VASILJEVIC, D.; BRANKOVIC, C.; CARDINALI, C.; GAFFARD, C.; HOLLINGSWORTH, A.; JAKOB, C.; JANSSEN, P.; KLINKER, E.; LANZINGER, A.; MILLER, M.; RABIER, F.; SIMMONS, A.; STRAUSS, B.; THÉPAUT, J-N.; VITERBO, P. THE ECMWF IMPLEMENTATION OF THREEDIMENSIONAL VARIATIONAL ASSIMILATION (3D-VAR). PART III: EXPERIMENTAL RESULTS. ECMWF NEWSLETTER, N. 81, P. 9, 1998

BARKER, D. M.; HUANG, W.; GUO Y. -R.; XIAO, Q. N. A THREE-DIMENSION (3DVAR) DATA ASSIMILATION SYSTEM FOR USE WITHMM5: IMPLEMENTATION AND INITIAL RESUlTS. MON. WEATHER REV., V. 132, P. 897-914, 2004.

BARKER, D. M.; HUANG, W.; LIU, Z.; AULIGNÉ, T.; ZHANG, X.; RUGG, S.; AJJAJI, R.; BOURGEOIS, A.; BRAY, J.; CHEN, Y.; DEMIRTAS, M.; GUO, Y. -R.; HENDERSON, T.; HUANG, W.; LIN, H. C.; MICHALAKES, J.; RIZVI, S.; ZHANG, $X$. THE WEATHER RESEARCH AND FORECASTING MODEL'S COMMUNITY VARIATIONAL/ENSEMBLE DATA ASSIMILATION SYSTEM: WRFDA. BULLETIN OF AMERICAN METEOROLOGICAL SOCIETY, V. 93, P. 831-843, 2012.

CPTEC/INPE. PÁgINA DO CENTRO DE PREVISÃo DE TEMPO E Estudos Climáticos do INSTITUTO NACIONAL DE PESQUISAS ESPACIAIS. 2014. DISPONÍVEL EM: < HTTP://TEMPO.CPTEC.INPE.BR/BOL_TECNICO .SHTML $>$. ACESSO EM: 20 AGO. 2014.

GOES. PÁgina dA Divisão de SATÉLITES DO CPTEC/INPE. 2012. DISPONÍVEL EM: < HTTP://SATELITE.CPTEC.INPE.BR>. ACESSO EM: 24 OUT. 2012.

HUANG, X. -Y.; XIAO, Q.; BARKER, D. M.; ZHANG, X.; MICHALAKES, J.; HUANG, W.; HENDERSON, T.; BRAY, J.; CHEN, Y.; MA, Z.; DUDHIA, J.; GUO, Y.; ZHANG, X.; WON, D. -J.; LIN, H. -C.; 
KUO, Y. H. FOUR-DIMENSIONAL VARIATIONAL DATA ASSIMILATION FOR WRF: FORMULATION AND PRELIMINARY Results. MON. WEATHER REV., V. 137, P. 299-314, 2009.

INMET. PÁGINA DO INSTITUTO NACIONAL DE MeteOrologia. 2012. DisPONÍVEL EM: < WWW.INMET.GOV.BR>. ACESSO EM: 15 NOV. 2012.

INNOCENTINI, V. ; CAETANO NETO, E. ; HÄRTER, F. P. . A FiRST GUESS FIELD Produced by MERging Digital Filter AND NudgING TECHNIQUES. REVISTA BRASILEIRA DE METEOROLOGIA (IMPRESSO), V. 17, N.2, P. 125-140, 2002.

KALNAY, EUGENIA. ATMOSPHERIC MODELING, DATA ASSIMILATION AND PREDICTABILITY. CAMBRIDGE UNIVERSITY PRESS, CAMBRIDGE, 2003. 341P.

LORENC, A. C. ANALYSIS METHODS FOR NUMERICAL WEATHER PREDICTION. QUARTERLY JOURNAL OF ROYAL METEOROLOGY SOCIETY, V. 112, N. 474, P. 1177-1194, 1986.

LORENZ, E. DETERMINISTIC NONPERIODIC FLOW. J. ATMOS. SCI., V. 20, N. 2, P. 130-141, 1963.

OYAMA, MARCOS DAISUKE; ROCHA, EDSON José PAulino DA; NOBRE, CARlos AFONSO. ESTUDO PRELIMINAR SOBRE O TEMPO DE “SPIN UP” DA UMIDADE DO SOLO NO MODELO CLIMÁTICO DO CPTEC. ANAIS DO XI CONGRESSO BRASILEIRO DE Meteorologia, P. 1085-1094, RIO DE JANEIRO, 2000. CD-ROM. (INPE-10189PRE/5717). DISPONÍVEL EM: <http://urlib.net/cptec.inpe.br/ walmeida/2003/09.03.14.49>. ACESSO EM: 10 ABR. 2013.

RABIER, F.; MAHFOUF, J-F.; FISCHER, M.; JÄRVINEN, H.; SIMMONS, A.; BOUTTIER, F.; COURTIER, P.; HAMRUD, M.; HASELER, J.; HOLLINGSWORTH, A.; ISAKSEN, L.;
KLINKER, E.; SAARINEN, S; TEMPERTON, C.; THÉPAUT, J-N.; UNDÉN, P.; VASILJEVIC. RECENT EXPERIMENTS ON 4D-VAR AND FIRST RESULTS FROM A SIMPLIFIED KALMAN FiLTER. ECMWF NEWSLETTER, N. 81, P. 8, 1998.

RAKESH, V.; SINGH, R.; JOSHI, P. C. INTERCOMPARISON OF THE PERFORMANCE OF MM5/WRF WITH AND WITHOUT DATA ASSIMILATION IN SHORT-RANGE FORECAST APPLICATIONS OVER THE INDIAN REGION. MeteOrol. AtMos. Phys., V. 105, P. 133$155,2009$.

ROUTRAY, A.; MOHANTY, U. C.; RIZVI, S. R. H.; NIYOGI, D.; OSURI, K. K., PRADHAN, D. IMPACT OF DOPPLER WEATHER RADAR DATA ON NUMERICAL FORECAST OF INDIAN MONSOON DEPRESSIONS. QUARTERLY JOURNAL OF Royal Meteorology SOCIETy, V. 136, P. 1836-1850, 2010.

SASAKI, Y. AN OBJECTIVE ANALYSIS BASED ON THE VARIATIONAL METHOD. JOURNAL OF METEOROLOGICAL SOCIETY OF JAPAN, V. 36, N. 3, P. 77-88, 1958.

SCHULTZ, PAUl. AN EXPLICIT ClOUd PhySiCS PARAMETRIZATION FOR OPERATIONAL NuMERICAL WEATHER PREDICTION. MON. WEATHER REV., V. 123, P. 3331-3343, 1995.

SILVA, GUSTAVO LEITE DA; SILVA, ALEX SANTOS DA; YAMASAKI, YOSHIHIRO. VALIDAÇÃO DA ASSIMILAÇÃO DE DADOS NA INFERÊNCIA DA REFLETIVIDADE DE UM DE UM RADAR COM O SISTEMAMM5. REVISTA BRASILEIRA DE METEOROLOGIA, V. 27, N. 1, P. 75-84, 2012.

SUGIMOTO, S.; CROOK, N. A.; SUN, J.; XIAO, Q.; BARKER, D. M. AN EXAMINATION OF WRF 3DVAR RADAR DATA ASSIMILATION ON ITS CAPABILITY IN RETRIEVING UNOBSERVED VARIABLES AND FORECASTING PRECIPITATION THROUGH OBSERVING SYSTEM SIMULATION EXPERIMENTS. MON. WEATHER REV., V. 137, P. 4011-4029, 2009. 
WANG, WEI; BRUYÈRE, CINDY; DUDA, MICHAEL; DUDHIA, JIMY; GILL, DAVE; LIN, HUI-CHUAN; MICHALAKES, JOHN; RIZVI, SYED; ZHANG, XIN; BEEZLEY, JONATHAN D.; COEN, JANICE L.; MANDEL, JAN. ARW VERSION 3 MODELING SYSTEM USER'S GUIDE. Mesoscale \& Microscale Meteorology DiVISION, NATIONAL CENTER FOR ATMOSPHERIC RESEARCH, 2012.

ZOU, X.; XIAO, Q. STUDIES ON THE INITIALIZATION AND SIMULATION OF A MATURE HURRICANE USING A VARIATIONAL BOGUS DATA ASSIMILATION SCHEME. J. ATMOS. SCI., V. 57, P. 836-860, 2000. 